\title{
An Improved Three-Level Shunt Active Filter
}

\author{
Simon Round, Hamish Laird, Richard Duke \\ Department of Electrical and Electronic Engineering \\ University of Canterbury, Christchurch, New Zealand \\ s.round@elec.canterbury.ac.nz
}

\author{
Colin Tuck \\ Preston Consulting \\ Christchurch, New Zealand \\ cjt@clear.co.nz
}

\begin{abstract}
A shunt active filter is capable of removing harmonic currents from the supply of commercial and industrial sites. This paper presents a novel method for generating the compensating current signal for an active filter that uses a three-level inverter to provide a fast transient response. It is shown that the active filter must be positioned downstream of the power factor correction capacitors for stable operation. A new compensating current technique, based on sinusoidal subtraction, together with the faster response of the three-level inverter produces a shunt active filter system that has superior performance compared to traditional two level systems.
\end{abstract}

\section{Introduction}

As interest in power quality becomes greater the practical application of low-voltage shunt active filters is growing increasingly attractive [1]. The ability to change operation when loads change and the rugged nature of modern switching converters mean that shunt active filters are well suited to application in commercial and industrial situations. In most three phase, four wire applications the total load is generally unknown and therefore it should be assumed that each phase carries a different current and there will be a neutral current. This assumption has implications on the design of both the shunt active filter controller and power electronics inverter.

The inverter and control system must be designed for a three phase, four-wire power system connection where each phase should operate independently. In addition if a commercial active filter unit is to be marketed successfully then a number of practical installation and operating parameters need to be taken into account. These include the operation of the shunt active filter with power factor correction capacitors and the installation of the unit in new and existing switchboards. This paper discusses the issues associated with a practical active filter and these include a comparison of harmonic detection methods, the design and performance of a novel control system and the design of an inverter with a fast transient response.

\section{Active Filter Connection Considerations}

The current measurement connection of shunt active filters to an AC system can be made in two ways as shown schematically in Figure 1. The first type of connection, called load side operation, measures the load current downstream of the active filter and produces a compensating current that cancels the harmonic currents from the load. The second system measures the supply current upstream of the active filter and uses a feedback action to eliminate the harmonic currents. The sign convention adopted in this analysis of shunt active filter performance is as shown in Figure 1.

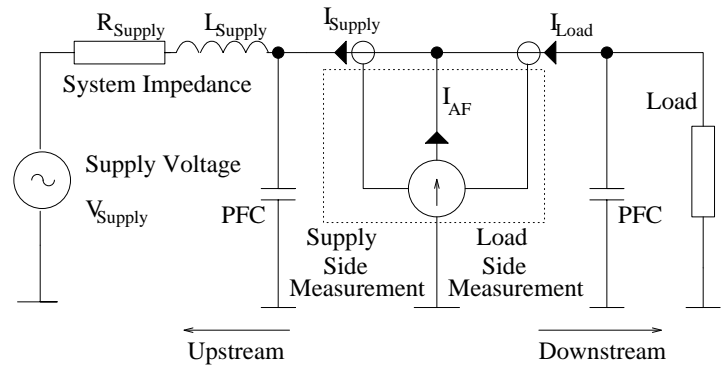

Figure 1: Active Filter and PFC Connection Options

This leads to active filter control laws for the supply side and load side measurement as given in Equations (1) and (2) respectively.

$$
\begin{aligned}
& I_{A F}=-k I_{\text {Supply }} \\
& I_{A F}=-I_{\text {Load }}
\end{aligned}
$$

The negative sign indicates that the active filter closes a feedback loop with negative gain so the gain and phase margins from frequency plots, as discussed in later sections, are classical.

The principle implications of the choice of the control method are the physical requirements of the inverter installation and the positioning of power factor correction capacitors in the network. 


\subsection{Power Factor Correction Capacitors}

Consumer power factor correction capacitors are, in general, connected at the low voltage (415V) level in New Zealand. They are usually connected at the switchboard's incoming feeder immediately downstream from the supply transformer so that the power factor can be controlled for the entire site load. Current trends in New Zealand are for supply companies to demand that the load power factor be close to unity at all times with the traditional $\mathrm{kVA}$ demand charge being phased out.

When the power factor correction capacitors are connected downstream of the active filter, as shown by the capacitor in the downstream direction in Figure 1, the forward transfers from the active filter current, $\mathrm{I}_{\mathrm{AF}}$, to the supply current, $\mathrm{I}_{\text {Supply }}$, and the load current, $\mathrm{I}_{\text {Load, }}$, are as shown in Figure 2. This is the transfer within the AC system and has no dependence on the active filter control system. The AC system component values for this example are given in Table 1 . These values are calculated from measured data from an industrial site. An active filter gain of 100 indicates that the supply harmonics are $1 / 101$ the magnitude of the load harmonics.
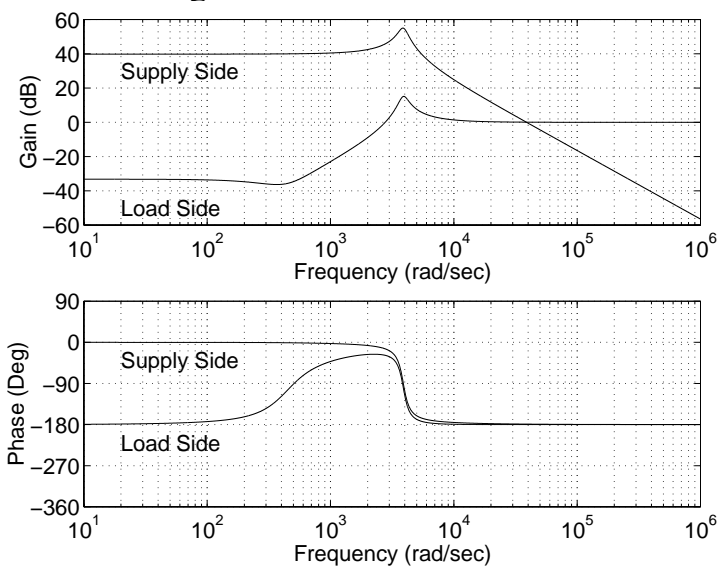

Figure 2: System Transfer Functions with Capacitors Downstream.

The bode plots of both supply side and load side with downstream capacitor placements shows that the phase margins are less than 10 degrees. This indicates that the closed loop system response when the active filter is connected will not be well damped and will be subject to transient oscillation [2].
Table 1: System Component Values

\begin{tabular}{|l|c|}
\hline \multicolumn{1}{|c|}{ Component } & Value \\
\hline \hline Supply Resistance, $\mathrm{R}_{\text {Supply }}$ & $0.03 \Omega$ \\
\hline Supply Inductance, $\mathrm{L}_{\text {Supply }}$ & $43.5 \mu \mathrm{H}$ \\
\hline Load Inductance, $\mathrm{L}_{\text {Load }}$ & $3.3 \mathrm{mH}$ \\
\hline Load Resistance, $\mathrm{R}_{\text {Load }}$ & $1.34 \Omega$ \\
\hline $\begin{array}{l}\text { Power Factor Correction } \\
\text { Capacitance, } \mathrm{C}_{\mathrm{PFC}}\end{array}$ & $1535 \mu \mathrm{F}$ \\
\hline $\begin{array}{l}\text { Supply Side Active Filter } \\
\text { Gain, } \mathrm{k}\end{array}$ & 100 \\
\hline
\end{tabular}

Connection of power factor correction capacitors upstream of the active filter results in stable operation. This can be seen in Figure 3, which shows the same two system bode plots when the power factor correction capacitors are upstream. The margins in this case are such that the system is stable.
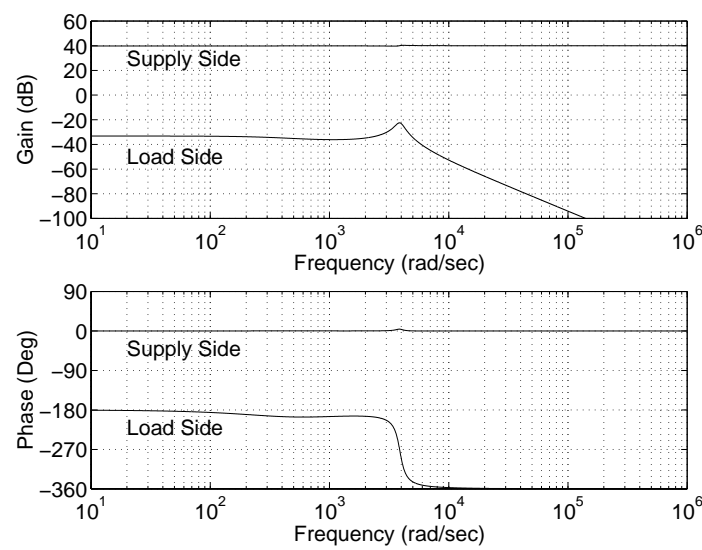

Figure 3: System Transfer Functions with Capacitors Upstream.

Insight into the mechanism by which the instability occurs can be gained by considering the example system in Figure 4. If the frequency in question is such that the impedance of the network seen by the active filter is capacitive, then that frequency is above the resonant frequency of $\mathrm{L}_{\text {Supply }}$ with $\mathrm{C}_{\mathrm{PFC}}$. In this case the active filter current, $\mathrm{I}_{\mathrm{AF}}$, leads the voltage, $\mathrm{V}_{\mathrm{PC}}$, by $90^{\circ}$ as almost all of the active current flows into the power factor correction capacitor, $\mathrm{C}_{\mathrm{PFC}}$. The current that flows in the supply, $\mathrm{I}_{\text {Supply }}$, lags the voltage, $\mathrm{V}_{\mathrm{PC}}$, by $90^{\circ}$. The control action given in Equation (1) means that if the active filter acts to increase $I_{\mathrm{AF}}$ the voltage, $\mathrm{V}_{\mathrm{PC}}$, is such to then increase $I_{\text {Supply }}$ which in turn increases $\mathrm{I}_{\mathrm{AF}}$, increasing $\mathrm{V}_{\mathrm{PC}}$ and again $\mathrm{I}_{\text {Supply. This is a }}$ positive feedback condition resulting in oscillation. The effect of the load and supply 
resistance is to provide damping but as is demonstrated by the bode plot in Figure 2 the system transfer has low phase margin indicating low damping and oscillatory transient response to a disturbance.

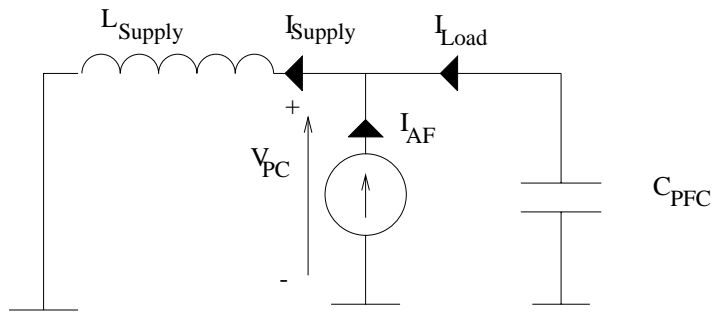

Figure 4: Instability Mechanism for Active Filter with PFC Downstream

\subsection{Switchboard Considerations}

Installing a shunt active filter into an existing switchboard involves making both a suitable power and measurement connection as shown schematically in Figure 1 and physically in Figure 5.

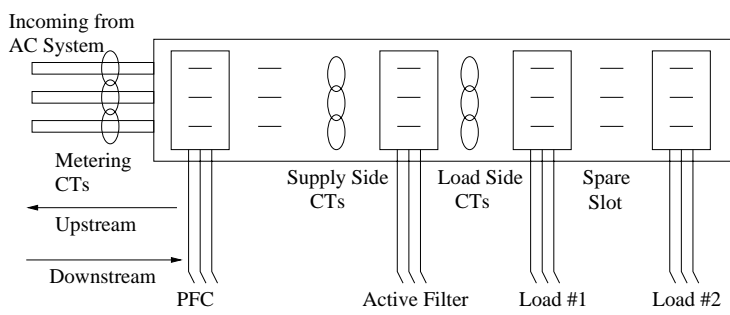

Figure 5: Installation of an Active Filter in a Switchboard

For a supply side measurement system it is possible to use the metering Current Transformers (CTs). Testing of typical metering CTs has shown that they are suitable for use as active filter input transducers. In some cases CTs may not provide a suitable level of performance and additional CTs must be installed. The use of metering CTs would allow possible cost savings in the installation of the unit. The disadvantage with this method is that any power factor correction capacitors connected will be immediately downstream of the CTs. This connection can cause instability in the filter operation as was discussed in section 2.1.

Operation in a load side configuration means that the filter must be connected upstream of the CTs which excludes the use of the metering CTs and therefore requires dedicated active filter CTs. Load side shunt active filter operation also suffers from instability if capacitors are connected downstream of the CTs. This is unusual but an induction motor may have dedicated power factor correction that could cause this instability.

For supply side measurement the active filter can be placed anywhere downstream of the measurement CTs. For example if the switchboard has a spare slot near the downstream end of the switchboard then the active filter could be placed there and still operate correctly with the CTs in the supply side CT position shown in Figure 2. However in the case of the load side system the CTs must be immediately downstream of the active filter. For an existing switchboard the installation of a load side active filter could require the complete rearrangement of the board, an expensive exercise

\section{Active Filter Inverter Design and Performance}

Traditional active filter inverter topologies are based on six-switch inverters. These inverters are generally constructed from IGBT modules. These modules generally limit the maximum switching of the active filter's inverter to around $10 \mathrm{kHz}$. In order to be able to follow high order harmonic components at the full current rating, the inverter must be capable of producing a high rate of change of compensating current. As an example, if the inverter has a current rating of $70 \mathrm{~A}_{\mathrm{RMS}}$ and can produce up to the $15^{\text {th }}$ harmonic at this rating then the maximum rate of change of compensating current is $0.4 \mathrm{~A} / \mu \mathrm{s}$. To achieve this value the series inductance would have to be $200 \mu \mathrm{H}$ assuming that inverter's DC voltage is $100 \mathrm{~V}$ greater than the peak of the supply voltage. This value of inductance is very low and this would result in the inverter requiring a very high switching frequency to maintain current control. A design compromise is to assume that the $\mathrm{dc}$ bus voltage is $200 \mathrm{~V}$ higher than the supply voltage. This would result in a design value of around $500 \mu \mathrm{H}$ for the series inductor. For most devices this still produces either a switching frequency that is too high or a hysteresis current that is too large. For example the maximum switching frequency of the inverter is $54 \mathrm{kHz}$ when $V_{D C}$ is $200 \mathrm{~V}$ higher than the peak of the AC supply voltage given a $500 \mu \mathrm{H}$ inductance 
and a current control accuracy of 10A. The lower bound of the band of switching frequencies is $30 \mathrm{kHz}$. These are at the top end of switching rates for IGBTs.

To reduce the average switching frequency to a realistic value, a three-level inverter, as shown in Figure 6 has been constructed using discrete IGBT and diodes. The use of discrete devices produces a cost-effective inverter and allows a non-standard topology to be used.

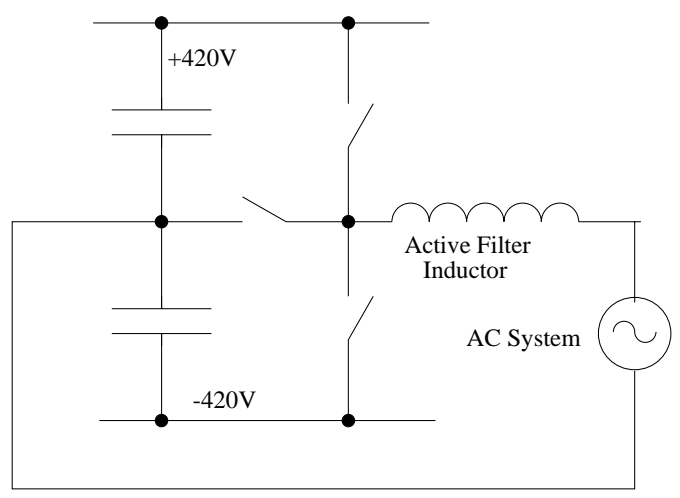

Figure 6: Three-Level Inverter

The output voltage level applied to the series inductor is now either $+420 \mathrm{~V}, 0 \mathrm{~V}$ or $-420 \mathrm{~V}$ instead of $\pm 420 \mathrm{~V}$ for the two-level case. The additional switch and the mid-point connection enable the average switching frequency to be reduced for the same value of inductance. Thus the active filter can follow higher order harmonic components at rated current.

Figure 7(a) shows the output current response of both two and three level inverters. The operating dc bus voltage level is assumed constant for both inverters at $\pm 400 \mathrm{~V}_{\mathrm{DC}}$ and the series inductor has been sized so that the average switching frequency for both inverters is approximately $10 \mathrm{kHz}$. The inductor size for the two-level inverter is $1.5 \mathrm{mH}$ and this is two times larger than the inductor in the three-level inverter. The lower inductance value gives the three-level inverter a faster response when subject to a step change in the reference current signal as seen in Figure 7(a).

The output inverter voltage is shown in Figure 7(b) and it can be seen that the maximum voltage change at the output is $400 \mathrm{~V}$ in the case of the three level compared to $800 \mathrm{~V}$ for the two level inverter.
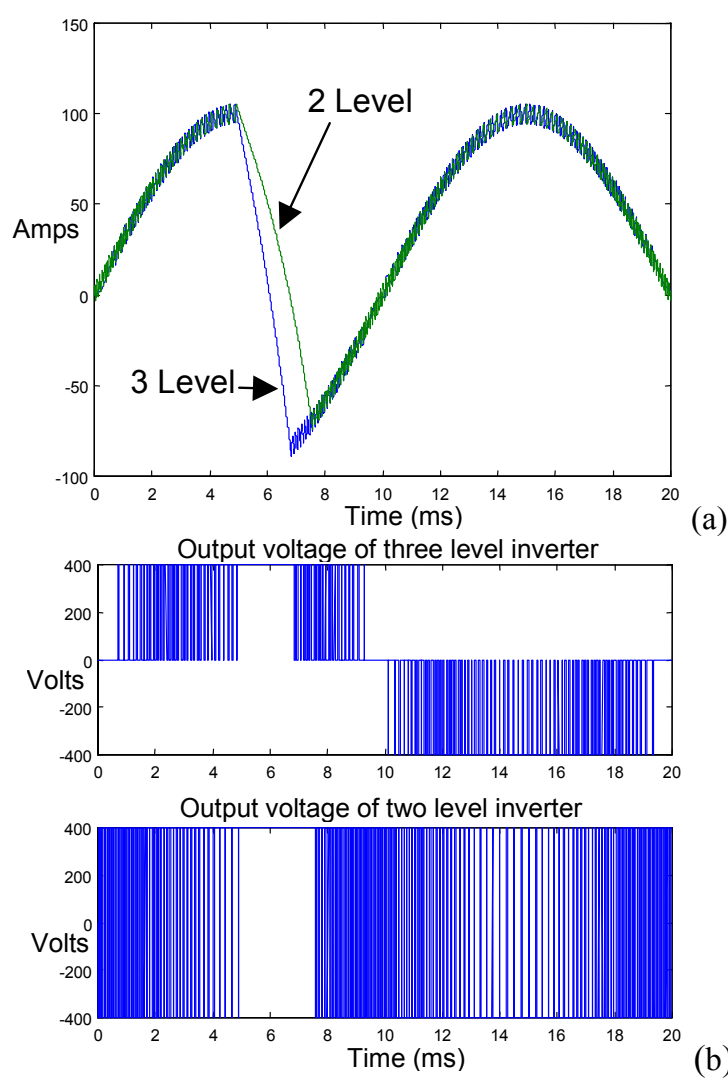

(b)

Figure 7: Comparison of Two and Three Level Inverters (a) Response of output current (b) inverter voltage waveforms.

\section{Harmonic Isolation Methods}

The fast transient response of the active filter inverter is necessary to ensure good harmonic compensation performance. However the response of the active filter to transient load or system changes depends also on the harmonic detection system and the bus voltage control system.

\subsection{Three Phase Methods}

Three phase active filter control systems are designed considering all the phases as one system. The typical structure of the system used to implement the synchronous reference frame (SRF) [3] method and the instantaneous reactive power theorem (IRPT) [4] is shown in Figure 8. By representing three phases as two phases, representative real and reactive powers can be formed using the vector rotator that effectively takes the dot and cross products of two vectors. The representative powers are frequency shifted so that positive sequence components appear at 
frequency zero (DC). This allows filters to remove or pass these components. The vector rotation is then reversed to return the frequency components back to the initial frequencies. The final output can be used as a reference or an error signal for load side or supply side active filters respectively. The principal difference between the SRF and the IRPT is the use of the Phase Locked Loop (PLL) in the SRF. This means that the vector rotator moves only fundamental frequencies to DC. The IRPT moves any component that occurs in both the voltage and current to DC. There are extensions to the IRPT [5] that allow the system to operate in four wire systems and other methods that make the active filter draw current to make the load appear a resistor [6].

The transient response of the IRPT and SRF are determined by the design of the filters used in the system. The frequency modulation effect is such that the natural response of the filters in the control system determines the rate of decay of any transient.

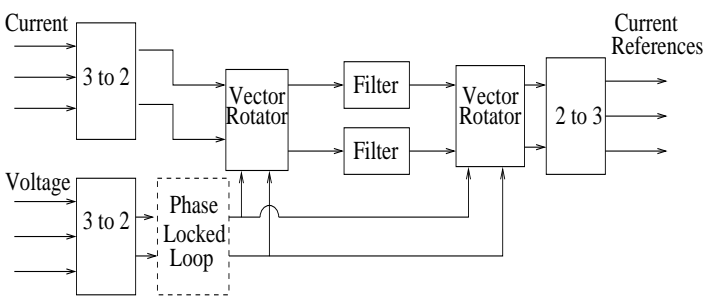

Figure 8: Typical Three Phase Active Filter Control System

A concern with three phase methods is the inability to operate without balancing the phase currents [7]. Any negative sequence fundamental component appears as twice the fundamental frequency after the vector rotator so it is treated as harmonic current and therefore compensated. This leads to excessively large active filter converters in situations with unbalanced loads where there is no requirement for phase balancing.

\subsection{Single Phase Methods}

Single-phase control methods treat the AC system as being made of three single phases with a common neutral. A single-phase phase-toneutral solution is therefore suitable. As the inverter used in the commercial active filter has a neutral point there is no device number penalty over an integrated three-phase solution. Possible single-phase harmonic detection methods are the fast fourier transform (FFT) method, the notch filter method and the sinusoidal subtraction method [7]. These single-phase systems operate in such as way as to not perform phase balancing.

In a notch filter there is a compromise between notch width and the natural response of the filter. By choosing the width of the notch filter the transient response of the active filter can be determined. The FFT method has been investigated [7] but the processing time required produces a delay in the harmonic information and results in poor transient performance.

Of all the methods available perhaps the two most cost effective methods are the Notch Filtering and the Sinusoidal Subtraction Method. All the other methods require powerful digital processing systems with their added cost penalty. This is to be avoided in a relatively small rated commercial active filter unit.

\subsection{Method Implemented}

The sinewave subtraction method has been implemented in a commercial active filter. This method uses a synthetic sinewave to remove the fundamental frequency component and is shown in Figure 9.

A phase locked loop is used to generate the synthetic sinusoid in phase with the fundamental component of the load current which is obtained by subtracting the active filter current from the supply current. The magnitude of the reference sinewave is controlled by the inverter's DC bus voltage controller which is designed to give both good compensation and an excellent transient response. The switching controller uses the difference between the supply current and the reference and produces a switching pattern to control the active filter current that makes the supply current follow the reference. The performance of the commercial active filter is demonstrated by Figure 10, which shows the distortion level of the measured supply current in an office block as the load changes. This change is caused by the operation of an elevator. As can be seen the total harmonic distortion (THD) is maintained at a low level of close to $5 \%$ even though the load distortion changes as the elevator starts operating at a time of 5.5 seconds. 


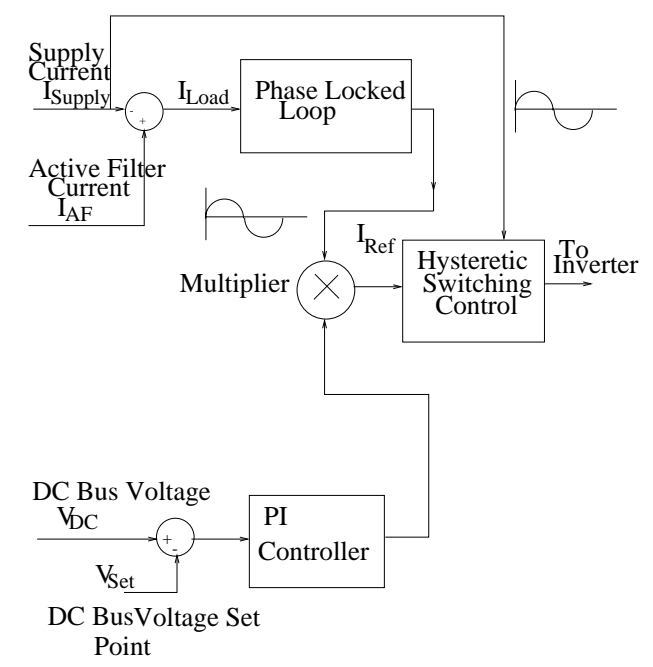

Figure 9: Active Filter Control System

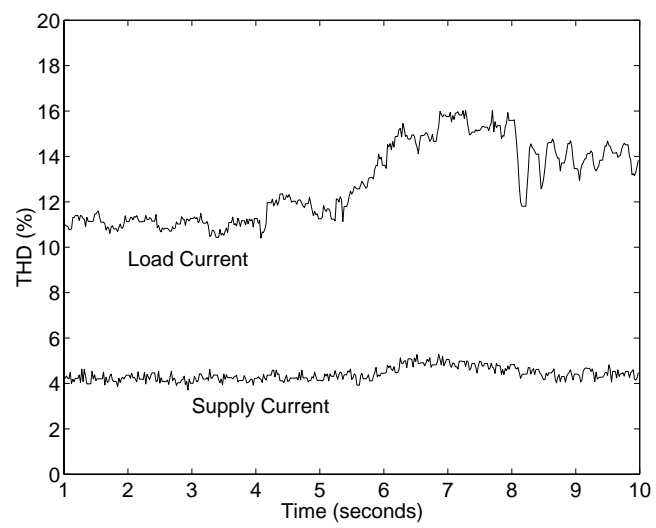

Figure 10: Distortion of Supply and Load Current showing the transient response of the Active Filter

\section{Conclusions}

A commercially available shunt active filter using a three-level inverter and a sinusoidal subtraction method of harmonic current isolation has been presented. The performance of the shunt active filter is such that it provides good reduction of harmonic currents and a fast transient response to changing loads.

It has been shown the power factor correction capacitors must be installed upstream of shunt active filters in order for the system to operate in a stable manner. This is true for both load and supply side connected shunt active filters.

The three level inverter topology allows the use of lower value output inductance which means that the rate of change of output current is higher for the three level inverter than for a comparable two level inverter with the same switching frequency. This allows the filter to compensate for higher order harmonics more effectively. The sinusoidal subtraction and DC bus control system ensures both excellent harmonic compensation and transient response.

\section{Acknowledgments}

The authors acknowledge the cooperation and financial support of Metalect Industries (New Zealand) Ltd.

\section{References}

[1] H. Akagi, "New Trends in Active Filters for Power Conditioning," IEEE Transactions on Industry Applications, vol. 32, no. 6, pp. 13121322, 1996.

[2] H. Akagi, "Control Strategy and Site Selection of a Shunt Active Filter for Damping of Harmonic Propagation in Power Distribution Systems," IEEE Transactions on Power Delivery, vol. 12, no. 1, pp. 354-363, 1997.

[3] S. Bhattacharya, A. Veltman, D. M. Divan, and R. D. Lorenz, "Flux-Based Active Filter Controller," IEEE Transactions on Industry Applications, vol. 32, no. 3, pp. 491-502, 1996.

[4] H. Akagi, A. Nabae, and S. Atoh, "Control Strategy of Active Power Filters Using Multiple Voltage Source PWM Converters," IEEE Transactions on Industry Applications, vol. 22, no. 3, pp. 460-465, 1986.

[5] F. Z. Peng, "Reactive Power and Harmonic Compensation Based on the Generalised Instantaneous Reactive Power Theory for ThreePhase Power Systems," International Conference on Harmonics and Quality of Power, Las Vegas, Nevada, USA, pp 83-89, 1996.

[6] V. Staudt, "Dynamic Parallel Compensation of Active Non-linear Loads using the FBDMethod," International Conference on Harmonics and Quality of Power, Las Vegas, Nevada, USA, pp 21-26, 1996.

[7] S. D. Round and D. M. E. Ingram, "An Evaluation of Techniques for Determining Active Filter Compensating Currents in Unbalanced Systems," European Power Electronics Conference, Trondheim, Norway, pp 4.767-4.772, 1997. 